\title{
A Computational Fluid Dynamics Study on Different Solar Chimney Designs on Solar Radiation
}

\author{
Hagar Alm EIDin Mohamad, Mohamad Elsamadony and Mohamed Ramon \\ Mechanical Power Department, Faculty of Engineering, Tanta University, Egypt. \\ Corresponding author email: mohammed134952@f-eng.tanta.edu.eg
}

\begin{abstract}
The solar chimney power plant (SCPP) is a hopeful solution to produce electrical power from solar energy. In this paper, a $2 D$ numerical study is presented to estimate the performance of the SCPPs while varying the collector angle, chimney diverging angle, variable solar radiation and ambient temperature and some geometrical designs. Numerical models run with solar load discrete ordinates (DO) and realizable $k-\varepsilon$ turbulence models. System is defined by the collector height $=50$ $\mathrm{mm}$, the chimney diameter $=160 \mathrm{~mm}$, the collector diameter $=2750$ $\mathrm{mm}$ and the chimney height $=3000 \mathrm{~mm}$. its investigated for each case the profile of magnitude velocity, air temperature, pressure, incident radiation and turbulence characteristics were presented. The effective choice of the best geometry is based on the maximum value of the air velocity inside the SCPP. Results indicates that a negative collector-roof positively increases the air velocity, and the output power. To a specific limit, increasing the diverging angle of the chimney has a god effect on the velocity magnitude and the other parameters. also Increasing the collector diameter and chimney height and diameter has a great effect on power output as shown in results.
\end{abstract}

Keywords- CFD, SCPP, solar chimney, simulation, ANSYS.

\section{INTRODUCTION}

Consumption of energy has been increasing every day because of the population growth around the world. Current energy resources like petroleum products may not stand for long to encounter people needs. The fast utilization of restricted fossil fuel and other conventional energy sources are the highest reasons for fuel lack in the world. This has formed awareness about alternate sources and therefore, more research is needed for non-conventional energy sources. Renewable energy uses sources that are repeatedly reloaded by nature like water, sun, heat of the earth, and wind.

\subsection{Historical review}

In this context, some researches for SCPP have been presented to enhance the solar setup. Ajeet Pratap Singh provided a performance enhancement strategies of a hybrid solar chimney power plant integrated with photovoltaic panel[1], Ali Asghar Sedighi studied the Effect of thermal energy storage layer porosity on performance of solar chimney power plant considering turbine pressure drop[2], Erdem Cuce indicate A thorough performance assessment of solar chimney power plants[3], Ekin ozgirgin presented a numerical study on the performance of a small-scale SCPP for different geometrical parameters[4], Ramakrishna balijepalli presented a detailed fabrication procedure, experiments and performance parameters evaluation of a small-scale (SCPP)[5], Pramod belkhode provided an evaluation of the experimental data to determine the performance of a solar chimney power plant[6], Seyyed hossein fallah studied The effect of artificial roughness of collector for SCPP[7], haythem nasraoui developed a novel collector design for enhancing the performance of SCPP[8], mohammed A. Aurybi provided a mathematical evaluation of SCPP collector combined with external heat source for noninterrupted power generation[9], M. Aligholami presented a hydrodynamic and thermodynamic improvement of a solar chimney power plant[10], Fei Cao studied a Full-year simulation of solar chimney power plants in Northwest China[11], Nima Fathi developed an efficiency enhancement of solar chimney power plant using the waste heat from nuclear power plant[12], Faisal M. Hussain presented a performance analysis of a SCPP design aided with reflectors[13], Fei Cao provided a design and simulation of a solar double-chimney power plant[14], Yangyang Xu studied the Performance of divergent-chimney solar power plants[15], P.J Cottam investigated a SCPP Dimension matching for optimum performance[16], Aakash Hassan developed a numerical investigation on performance of solar chimney by varying collector slope and chimney diverging angle[17], Siyang $\mathrm{Hu}$ presented a mathematical Modelling to the Performance of a Solar Chimney Power Plant with Divergent Chimneys[18], Ming-Hug Huang developed a twodimensional simulation method of the solar chimney power plant with a new radiation model for the collector[19].

\subsection{Solar radiation}

Egypt is situated on the north east of Africa that lies between $22^{\circ}$ and $31^{\circ} 36^{\square}$ in North latitude and $24^{\circ}$ and $37^{\circ}$ in East longitude. [20], as one of the sun-belt countries, Egypt is endowed with high intensity direct solar radiation as shown in Fig. 1.a, We take Aswan city for example as a perfect site in Egypt, the annual-average daily global irradiation value is $21.78 \mathrm{MJ} / \mathrm{m}^{2}$ and for diffuse irradiation it is $6.23 \mathrm{MJ} / \mathrm{m}^{2}$. For the normal incidence beam irradiation, the annual-average daily value is $24.46 \mathrm{MJ} / \mathrm{m}^{2}$. The annual-average daily fraction of the direct component of horizontal global radiation is 0.72 , respectively. The annual-average daily value for the clear sky index is 0.648 , and the average frequency of clear days annually is $77.6 \%$. [21] The amount of radiant energy emitted by the sun is called solar radiation, while solar irradiation refers to the quantity of solar radiation received from the sun per unit area which is expressed in $\left(\mathrm{kw} / \mathrm{m}^{2}\right)$, The solar atlas indicates that Egypt, as one of the sun-belt countries, is 
endowed with high intensity direct solar radiation of 2000 $3200 \mathrm{kWh} / \mathrm{m} 2 /$ year from north to south, as shown in "Fig. 1.a" [22], and this is the types of solar irradiation: -

Direct normal irradiation: - the amount of solar radiation received per unit area by a surface perpendicular (normal) to the rays that come in a straight line from the direction of the sun at its current position in the sky. "Fig. 1.b"

Diffuse horizontal irradiation: - is the amount of radiation received per unit area by a surface that does not arrive on a

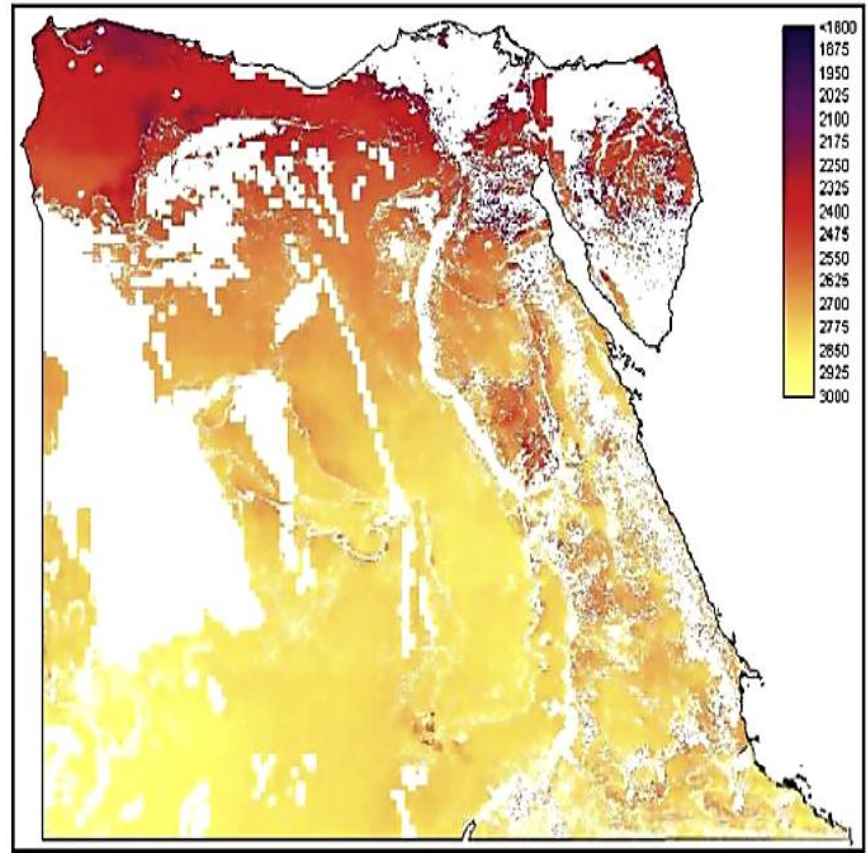

(a). Solar radiation intensity map for Egypt [22] direct path from the sun, but has been scattered by molecules and particles in the atmosphere. Basically, it is the illumination that comes from clouds and the blue sky.

Global horizontal irradiation: - the total amount of short-wave radiation received from above by a horizontal surface. This value is of particular interest to photovoltaic installation and includes both direct normal irradiance (DNI) and diffuse horizontal irradiance (DIF).

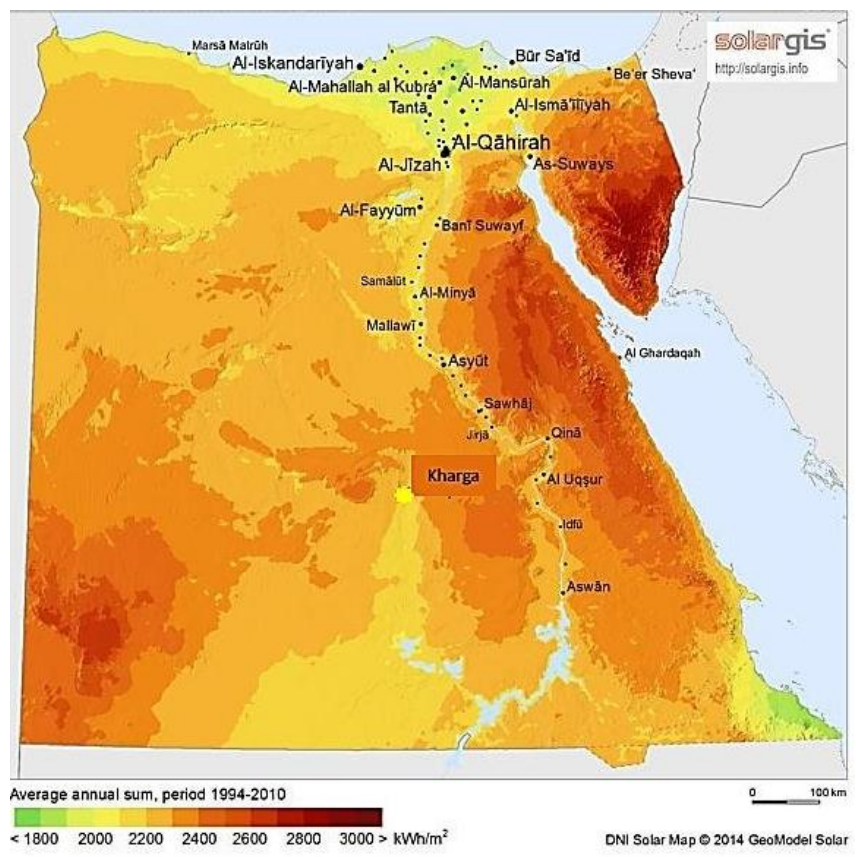

(b). direct normal irradiation [23]

Figure 1. Solar radiation maps for Egypt

\subsection{Solar chimney components}

\section{A. Collector}

The main component of a SCPP is the collector; collector is the part that produces the hot air using the greenhouse effect. It's made up of plastic or glass film. The height of the collector adjacent to the chimney base, therefore the air inters to the chimney with minimum friction loss. This material let the short-wave solar radiation component and keeps the longwave component from the heated ground. Thus, the ground below the collector heats the airflow radially from the outside to the chimney. The construction of the collector changes to the material we used.[24]

\section{B. Chimney}

A Chimney is the main part of the SCPP. The tower is located at the center of the collector and considering as the thermal engine for the plant. The tower makes a temperature difference between the top and the bottom. This makes the chimney effect, which moves air from the bottom of the chimney out from the top. It's also being an advantage to set the turbine in the chimney as low as we can to make its construction easier. [25]

\section{C. the power conversion unit (PCU)}

The turbine of the solar chimney is a very important part of the plant because it extracts the energy from air and transmits it to the generator. It has an important impact on the plant because the turbine pressure drop is coupled with plant mass flow rate. In solar chimneys the turbines are ducted, and their maximum theoretical efficiency is consequently $100 \%$. The direction of the airflow remains constant. The turbines are kept from harsh weather but have to handle higher temperatures. The large volume of both collector and chimney prevents large fluctuations in airflow speed. [26]

\section{SIMULATION}

The simulation of the chimney will be running on a small scale in order to get a precious result from ANSYS. the chimney height is $3000 \mathrm{~mm}$ and diameter is $160 \mathrm{~mm}$, the collector height and diameter are equal to $\mathrm{h}=50 \mathrm{~mm}$ and $\mathrm{D}=2750 \mathrm{~mm}$, respectively as shown in table 1 . After finishing 
the geometry design, the next step is meshing; meshing is one of the most important steps in our simulation because of its great effect on the solution process and the results. We should take care of elements number not to be very high in order not to make the solution process takes more time, another thing is to observe. Orthogonal quality, element quality, aspect ratio and skewness need to get ideal values of them as we can.

\subsection{Meshing data}

Element size $=0.003 \mathrm{~m}$, capture curvature and proximity, heigh smoothing and heigh element quality "Fig. 2," nodes number $=87454$, elements number $=87077$, aspect ratio $=1$, Element quality $=0.99947$, Orthogonal quality $=1$, Skewness $=1.4934 \mathrm{e}-10$

\subsection{Boundary condition}

The next step after meshing is setting up and solution under this boundary condition.

\subsection{Solution method}

- Pressure-velocity coupling: - simple

- Gradient: - least squares cell based

- Pressure: - standard

- Momentum, turbulent kinetic energy, turbulent dissipation rate, energy and discrete ordinates: - second order upwind.

Solution starting the solution with 500 iteration to make sure the solution is stable completed. "Fig. 4," shows the solution conveyance and number of iterations.

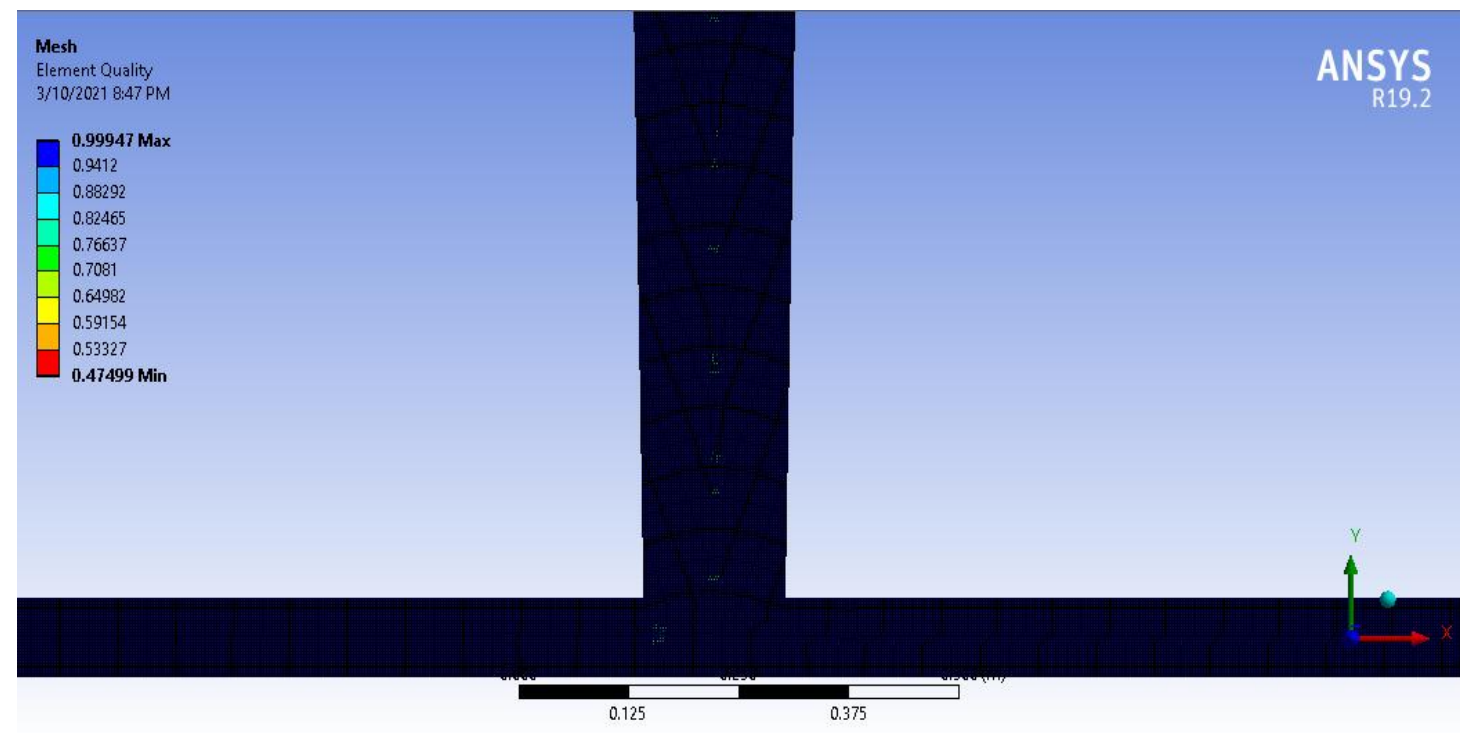

Figure 2. SCPP mesh

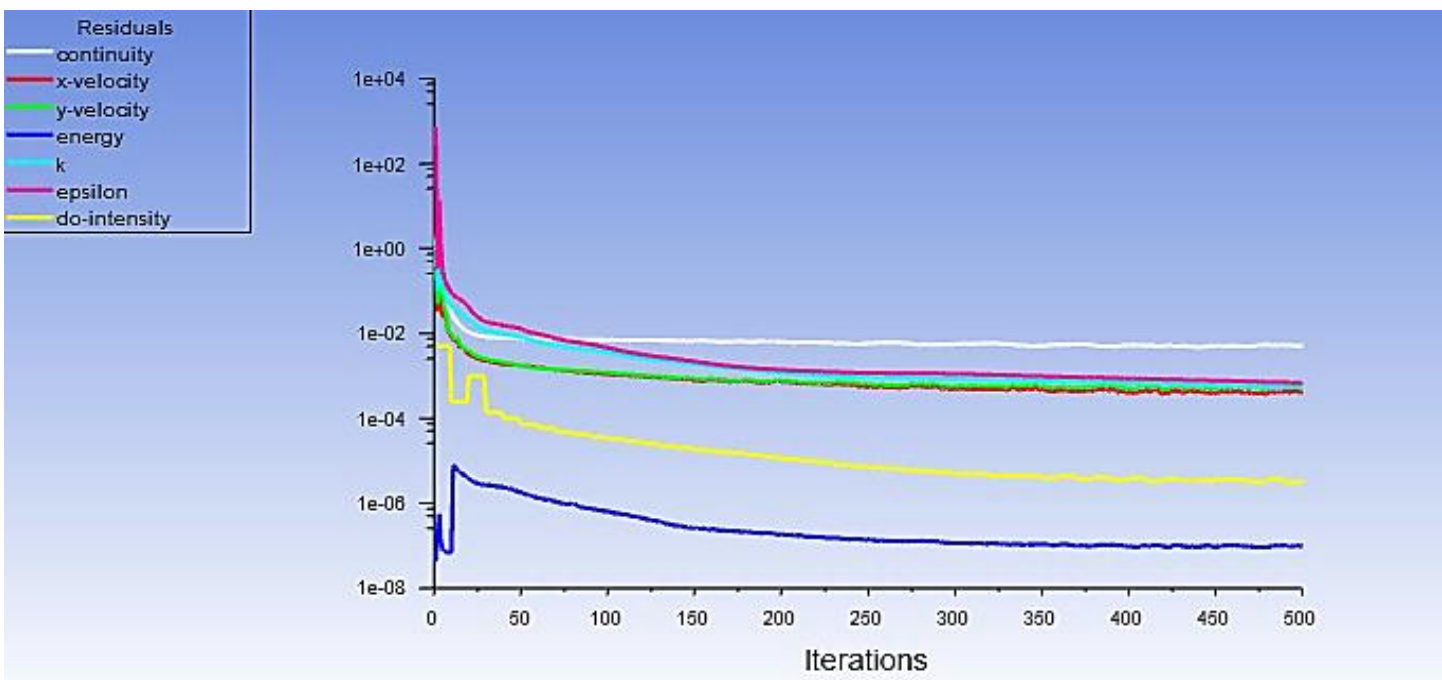

Figure 3. Solution convergence and number of iterations 
TABLE 1. Boundary conditions

\begin{tabular}{|l|l|}
\hline Inlet & Pressure inlet, $\mathrm{T}=307, \mathrm{P}=101325$ \\
\hline Outlet & Pressure outlet, $\mathrm{T}=307, \mathrm{P}=101325$ \\
\hline Absorber & $\begin{array}{l}\text { Wall, mixed thermal condition } \mathrm{h}=8 / \mathrm{T}=307, \\
\text { opaque }\end{array}$ \\
\hline Collector & $\begin{array}{l}\text { Wall, mixed thermal condition } \mathrm{h}=8 / \mathrm{T}= \\
307, \text { semitransparent radiation model with } \\
\text { direct irradiation } 800 \mathrm{w} / \mathrm{m}^{2}\end{array}$ \\
\hline Chimney & Wall, heat flux $=0$, opaque \\
\hline
\end{tabular}

After solution process completed, we get the final result for many values for the different cases we studying. For example, this is the velocity profile for the studding cases which shows the great effect of collector and chimney angle changing to get more velocity, mass flow rate and power.

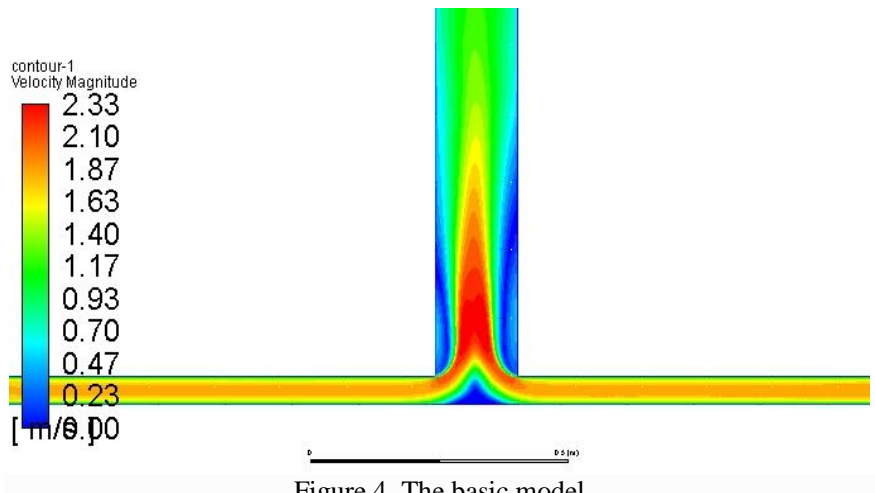

Figure 4. The basic model

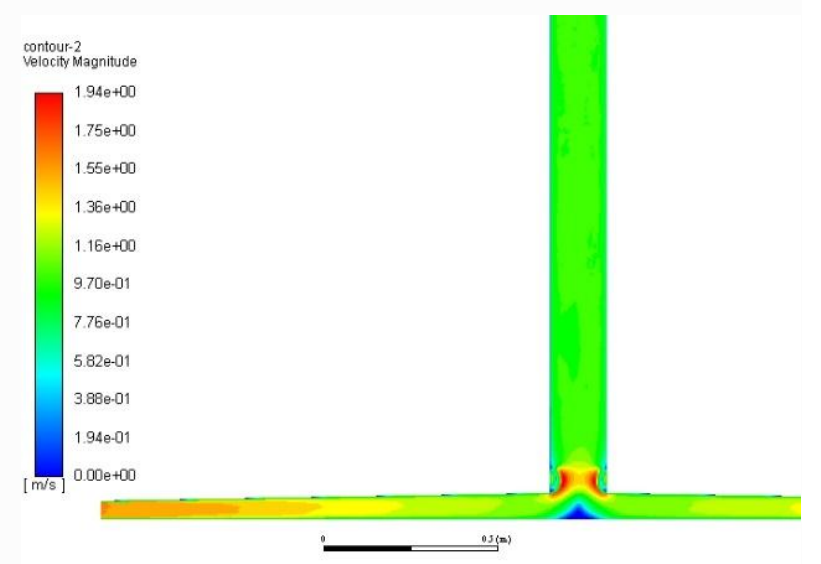

a. $\square=1$

\section{RESULTS}

\subsection{Basic model}

As shown in "Fig. 4" the magnitude velocity profile of the standard model $=2.33 \mathrm{~m} / \mathrm{s}$, which gives a power output of 1.2 kw.

\subsection{Inclined collector}

According to these results, we found that the significant value of the magnitude velocity appears at the bottom of the chimney for the considered angles. Away from the chimney, the magnitude velocity values are recorded very weak. Certainly, the magnitude velocity varies from one design to another.in table 2 . For $\beta=1^{\circ}, \beta=0^{\circ}$ and $\beta=-1.5^{\circ}$, the maximum magnitude velocity value is equal respectively to $\mathrm{V}=1.94 \mathrm{~m} . \mathrm{s}-1, \mathrm{~V}=2.33$ m.s-1 and V=2.34 m.s-1. It has been noted that the shape of the zone, surrounding the maximum values of the magnitude velocity, varies for different cases.

Computational results have shown that the thermodynamic efficiency of the solar plant increases with a negative angle of the collector roof. In fact, the value of the magnitude velocity can be raised by $125 \%$ inside the solar chimney power plant for a variation of $\Delta \theta=2.5^{\circ}$. The SCPP with a negative inclined collector roof is an efficient solution for the solar setups to increase the power output as shown in "Fig. 9".

\subsection{Chimney divergent angle}

The distribution of velocity for different chimney's diverging angles $(1,2)$ evaluated in "Fig. 6" the chimney inlet area and all other parameters were kept constant except the chimney outlet area. The results show that employing a diverging chimney leads to remarkable increase in velocity. Maximum velocity of $2.81 \mathrm{~m} / \mathrm{s}$ is achieved for case when diverging angle is 1 , while it reaches $2.80 \mathrm{~m} / \mathrm{s}$ for diverging angle of 2 .

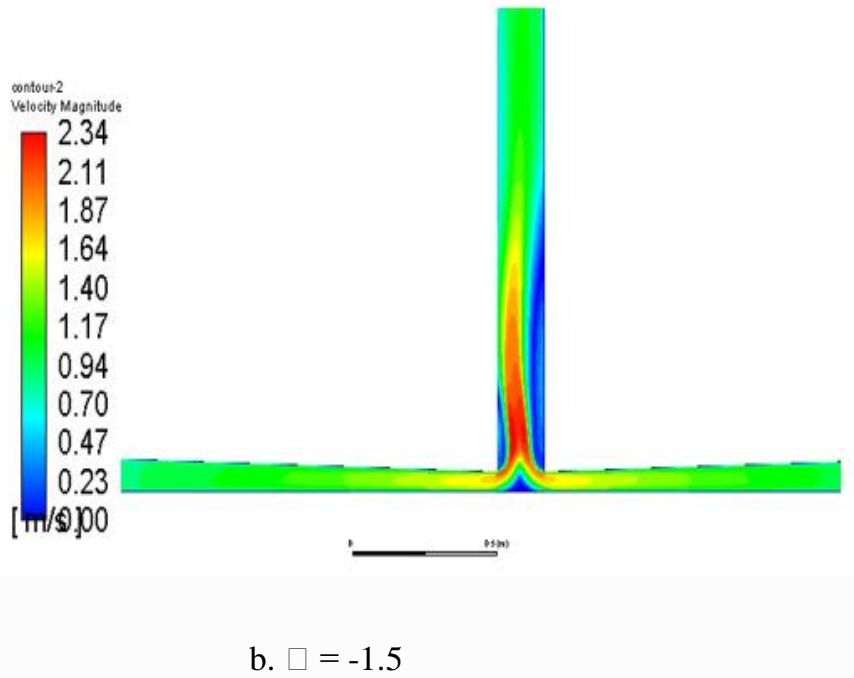




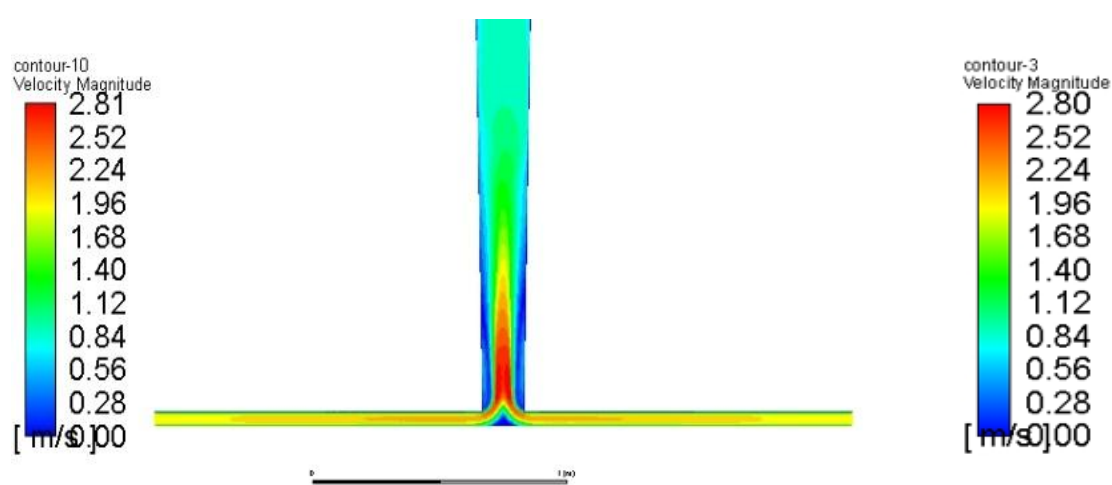

a. $\square=1$

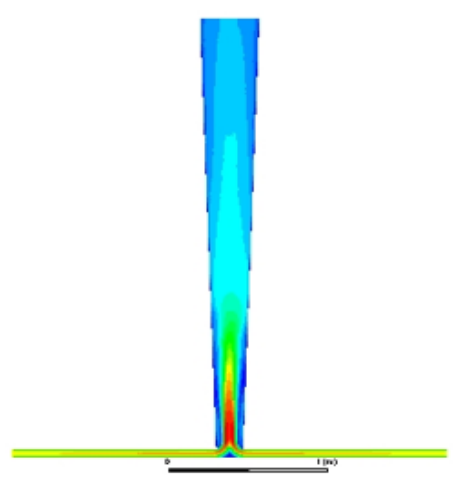

b. $\square=2$

Figure 6. Converging chimney

\subsection{Variable geometric parameters}

Investigation of chimney height, The $\mathrm{H}_{\mathrm{ch}}$ was changed from $3000 \mathrm{~mm}$ to $4000 \mathrm{~mm}$. The higher Hch corresponded with a higher level of efficiency and power. Velocity raised from 2.33 to 2.99 , Static pressure decreased from101321 to 101318 and static temperature raised from $319.09 \mathrm{k}$ to $320.22 \mathrm{k}$.

contour-1
Velocity 2.99 agitude
2.99
2.69
2.39
2.09
1.79
1.49
1.20
0.90
0.60
0.30
$[m / 50] .00$

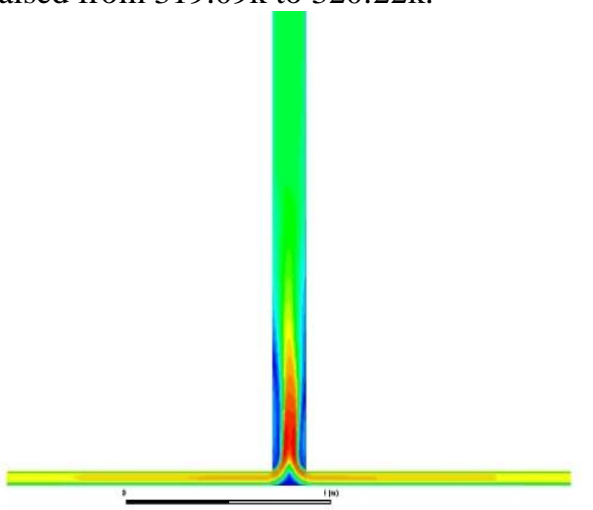

a. $\mathrm{H}_{\mathrm{ch}}=4000 \mathrm{~mm}$

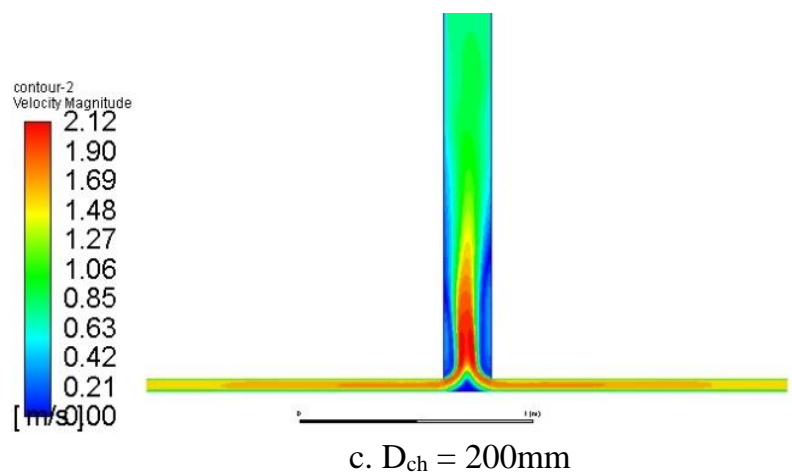

Investigation of collector diameter, changes to output power and solar chimney efficiency are indicated where the value of $\mathrm{D}_{\text {coll }}$ varies from $2750 \mathrm{~mm}$ to $4000 \mathrm{~mm}$, which means that flow power would be greater as shown in "Fig. 9".
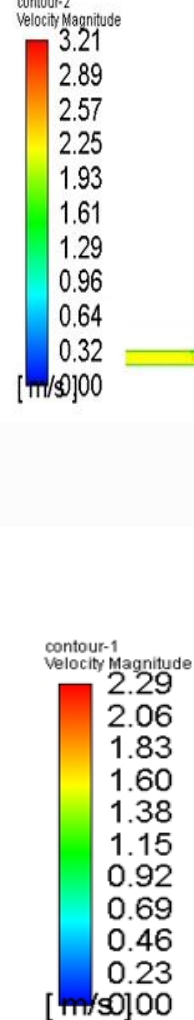

Figure 7. Variable geometry 


\subsection{Variable heat flux and temperature}

The results show the great effect of increasing the ambient temperature and radiation heat flux which increase the magnitude velocity to $2.56 \mathrm{~m} / \mathrm{s}$, static temperature to 344 and static pressure decrease to 101320.15 .

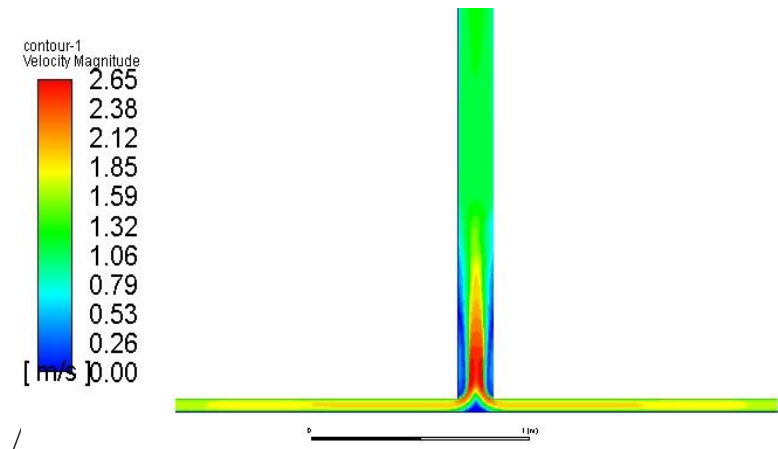

a. $q=1000, T=309$
All of this increase mass flow rate from 0.19689 to 0.21889 and power output as shown in "Fig. 9"

Figure 8. Variable q, $\mathrm{T}$

TABLE 2

Results for Variable Inclined Collector

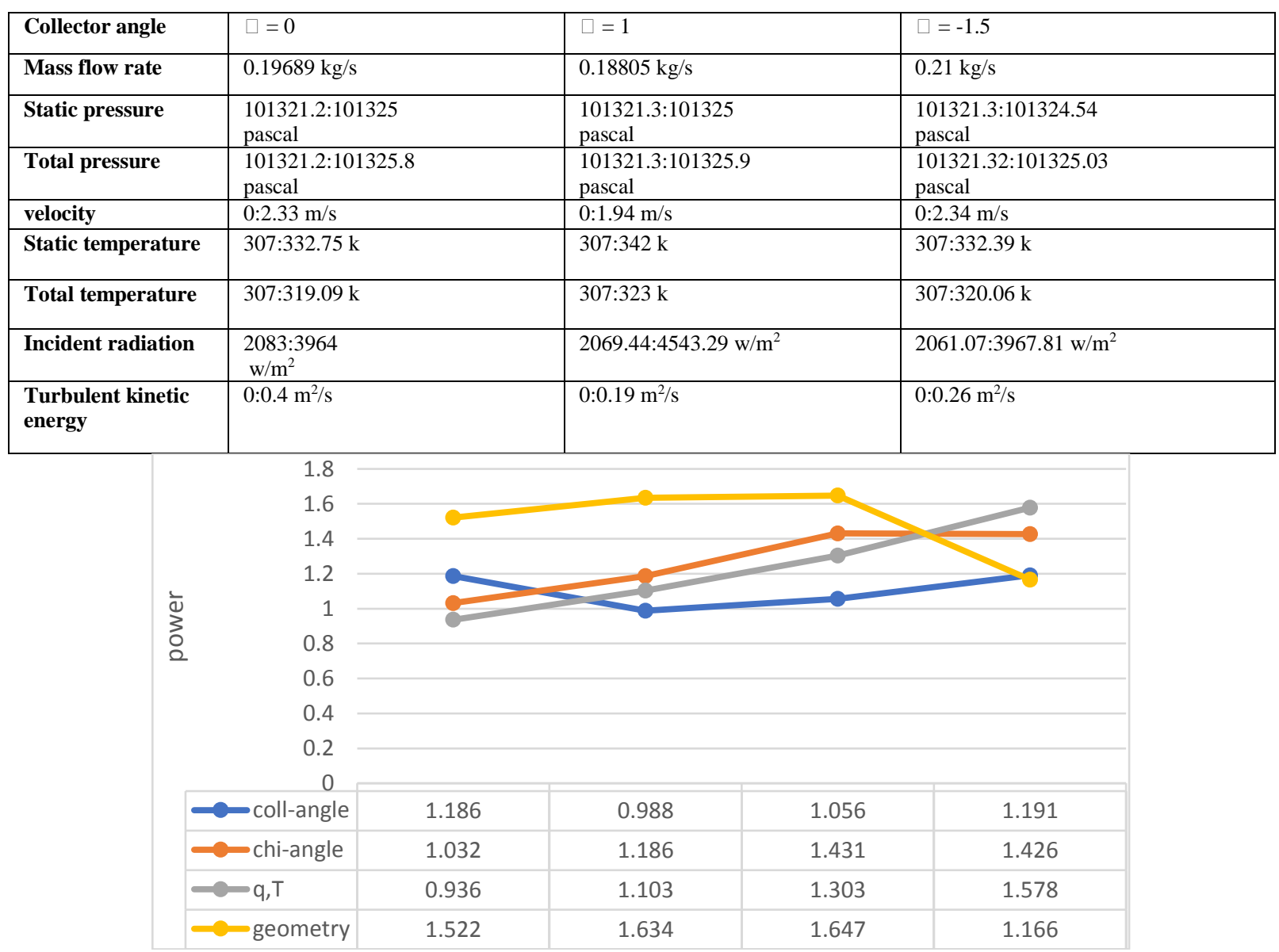

Figure 9. Output power for all cases 


\section{CONCLUSION}

In this paper, the impact of the collector roof inclination, chimney diverging, geometrical design and solar radiation and ambient temperature was simulated Computational results have shown that the thermodynamic efficiency of the solar plant increases with a negative angle of the collector roof. the value of magnitude velocity can be raised up by $125 \%$ inside the SCPP for a variation of $\Delta \theta=2.5^{\circ}$. The solar chimney with a negative inclined collector is an efficient solution to increase the power output. Similarly, the effect of chimney diverging angle shows the effect of increasing the angle from 0 to 2 gives a good effect on static and total pressure also on velocity profile which increasing the power output. And about geometrical designs, it's clear the great effect of increasing the collector diameter or chimney height on power output. The last simulation was on the effect of radiation and temperature which affects mainly on the temperature profile and gives better temperature profile

\section{REFRENCES}

1. Pratap Singh, A., et al., Performance enhancement strategies of a hybrid solar chimney power plant integrated with photovoltaic panel. Energy Conversion and Management, 2020. 218: p. 113020.

2. Sedighi, A.A., Z. Deldoost, and B.M. Karambasti, Effect of thermal energy storage layer porosity on performance of solar chimney power plant considering turbine pressure drop. Energy, 2020. 194: p. 116859.

3. Cuce, E., P.M. Cuce, and H. Sen, A thorough performance assessment of solar chimney power plants: Case study for Manzanares. Cleaner Engineering and Technology, 2020. 1: p. 100026.

4. Yapıcı, E.Ö., E. Ayli, and O. Nsaif, Numerical investigation on the performance of a small scale solar chimney power plant for different geometrical parameters. Journal of Cleaner Production, 2020. 276: $\mathrm{p}$. 122908.

5. Balijepalli, R., V.P. Chandramohan, and K. Kirankumar, Development of a small scale plant for a solar chimney power plant (SCPP): A detailed fabrication procedure, experiments and performance parameters evaluation. Renewable Energy, 2020. 148: p. 247-260.

6. Belkhode, P., C. Sakhale, and A. Bejalwar, Evaluation of the experimental data to determine the performance of a solar chimney power plant. Materials Today: Proceedings, 2020. 27: p. 102-106.

7. Fallah, S.H. and M.S. Valipour, Evaluation of solar chimney power plant performance: The effect of artificial roughness of collector. Solar Energy, 2019. 188: p. 175-184.

8. Nasraoui, H., Z. Driss, and H. Kchaou, Novel collector design for enhancing the performance of solar chimney power plant. Renewable Energy, 2020. 145: p. 1658-1671.

9. Aurybi, M.A., et al., Mathematical evaluation of solar chimney power plant collector, integrated with external heat source for noninterrupted power generation. Sustainable Energy Technologies and Assessments, 2018. 30: p. 59-67.

10. Aligholami, M., S. Sh. Khosroshahi, and A. R. Khosroshahi, Hydrodynamic and thermodynamic enhancement of a solar chimney power plant. Solar Energy, 2019. 191: p. 180-192.

11. Cao, F., et al., Full-year simulation of solar chimney power plants in Northwest China. Renewable Energy, 2018. 119: p. 421-428.

12. Fathi, N., et al., Efficiency enhancement of solar chimney power plant by use of waste heat from nuclear power plant. Journal of Cleaner Production, 2018. 180: p. 407-416.

13. Hussain, F.M. and F.A. Al-Sulaiman, Performance analysis of a solar chimney power plant design aided with reflectors. Energy Conversion and Management, 2018. 177: p. 30-42.

14. Cao, F., et al., Design and simulation of a solar double-chimney power plant. Renewable Energy, 2017. 113: p. 764-773.
15. $\mathrm{Xu}, \mathrm{Y}$. and $\mathrm{X}$. Zhou, Performance of divergent-chimney solar power plants. Solar Energy, 2018. 170: p. 379-387.

16. Cottam, P.J., et al., Solar chimney power plants - Dimension matching for optimum performance. Energy Conversion and Management, 2019. 194: p. 112-123.

17. Hassan, A., M. Ali, and A. Waqas, Numerical investigation on performance of solar chimney power plant by varying collector slope and chimney diverging angle. Energy, 2018. 142: p. 411-425.

18. $\mathrm{Hu}, \mathrm{S}$. and D.Y.C. Leung, Mathematical Modelling of the Performance of a Solar Chimney Power Plant with Divergent Chimneys. Energy Procedia, 2017. 110: p. 440-445.

19. Huang, M.-H., et al., A two-dimensional simulation method of the solar chimney power plant with a new radiation model for the collector. International Communications in Heat and Mass Transfer, 2017. 85: p. 100-106.

20. Mosalam Shaltout, M.A. and M.T.Y. Tadros, Typical solar radiation year for Egypt. Renewable Energy, 1994. 4(4): p. 387-393.

21. Omran, M.A., Analysis of solar radiation over Egypt. Theoretical and Applied Climatology, 2000. 67(3): p. 225-240.

22. Khalil, A., A. Mubarak, and S. Kaseb, Road map for renewable energy research and development in Egypt. Journal of Advanced Research, 2010. 1: p. 29-38.

23. Abdelhady, S., et al., A Preliminary Technical and Economic Assessment of Electric Power Generation Using Stirling Dish in Western Desert of Egypt. 2018.

24. Ahmed, I., N. Ali, and B. Salam, DESIGN \& FABRICATION OF A SOLAR CHIMNEY POWER GENERATION SYSTEM. 2017.

25. Peinado Gonzalo, A., A. Pliego Marugán, and F.P. García Márquez, $A$ review of the application performances of concentrated solar power systems. Applied Energy, 2019. 255: p. 113893.

26. Toghraie, D., et al., Effects of geometric parameters on the performance of solar chimney power plants. Energy, 2018. 162. 